\title{
EDITORIAL
}

\section{Laudato Si'}

En el context post Rio+20, amb una crisi econòmica persistent que, paradoxalment, sembla reforçar les dinàmiques extractivistes i desenvolupistes del metabolisme social global, les posiciones polítiques clares i determinades en relació amb la necessitats de canvis profunds en la relació entre els éssers humans i la naturalesa, i en la distribució dels recursos no han estat abundants en l'arena internacional. Per això, la carta encíclica Laudato Si' del Papa Francesc és un document de primera importància, que pot tenir una projecció molt rellevant en els debats ambientals a venir, ja que, justament, recapitulant una doctrina precedent que s'ha anat generant en el marc de les esglésies cristianes i, particularment, la catòlica, en relació amb la crisi ambiental, proposa un enfoc radical sobre aquesta qüestió, amb referències significatives a conceptes i idees que formen part de les posicions alternatives en el debat, com ara deute ecològic o decreixement.

El Papa Francesc és el cap de l'Església Catòlica, la qual cosa li concedeix un lideratge moral que va més enllà de la comunitat catòlica estricta. A més, no cal oblidar la seva condició de cap d'estat, malgrat que es tracti d'un estat minúscul, de menys de mig kilòmetre quadrat i menys de mil habitants, la Ciutat del Vaticà. No és banal que un cap d'estat, per petit que aquest sigui, emeti un document oficial en el que expressa la seva opinió sobre la crisi ambiental d'una manera tan radical. Encara ho és menys que aquest cap d'estat encapçali una de les confessions religioses més esteses i d'una tradició més densa i consolidada. Per aquest motiu, no pot sorprendre l'impacte que té i ha de tenir l'encíclica Laudato Si', saludada per molts ambientalistes com una aportació significativa i valenta al debat internacional sobre la manera d'afrontar la crisi ambiental.

L'encíclica fa una diagnosi completa de l'estat del medi ambient i apunta les causes principals de la crisi ambiental — concepte que també apareix literalment en el text-, així com els seus efectes, i marca una sèrie de línies polítiques, a partir d'uns quants conceptes clau en els grans debats del moment. És cert que l'encíclica reposa sobre una àmplia sèrie d'antecedents, que van des d'encícliques de papes anteriors, fins 
documents episcopals d'arreu del món, tot considerant aportacions més enllà de la mateixa Església Catòlica, com les del Patriarca Ecumènic Bertomeu. Tot i així, el caràcter comprensiu i la profunditat de Laudato Si', així com la seva estructurada radicalitat, converteixen aquest document en una novetat d'impacte difícilment menystenible en l'àmbit del dret ambiental, més quan aquest està sotmès a considerables pressions regressives en el context de les mesures d'estímul poc imaginatives que es prenen per afrontar la crisi econòmica. Es tracta d'un document valent i radical; valent perquè adopta una posició ben allunyada del que és el corrent dominant en els discursos dels estats, i radical perquè posa l'accent en l'arrel del problema, això és, el mateix funcionament del metabolisme social en el context del sistema-món capitalista.

L'encíclica repassa els diferents problemes que afecten el medi ambient mundial: des de la contaminació de l'aire i l'aigua als residus, des de la desforestació a la pesca insostenible o els riscos de la substitució de boscos o zones humides per monocultius, posant l'accent, per la seva extrema gravetat en el canvi climàtic $i$ la pèrdua de la biodiversitat. Tanmateix, subratlla que les qüestions ambientals no poden afrontar-se aïlladament. L'estat del medi ambient és l'altra cara del model de reproducció social, de la manera com l'organització social aprofita els recursos naturals, com interactua amb ells per generar els productes que requereix per satisfer les seves necessitats, com genera i utilitza l'energia que necessita per aquesta transformació, i com gestiona els residus que es deriven d'aquest procés.

Per aquest motiu, coincidint amb l'enfoc de la problemàtica ambiental que es proposa des de les diverses perspectives basades en la justícia ambiental, l'encíclica subratlla l'aspecte social de la qüestió. Així, es refereix als desplaçats forçosos a conseqüència del canvi climàtic; critica la privatització de l'aigua i defensa l'accés a l'aigua potable com a dret humà basic; apunta a què el control de l'aigua per part de grans empreses mundials es converteixi en una de les principals fonts de conflictes d'aquest segle; denuncia el deteriorament de la qualitat de la vida humana i la degradació social, especialment en les megaciutats, així com la manca d'equitat en la disponibilitat i el consum d'energia i d'altres serveis; assenyala els impactes socials derivats de les dinàmiques del món digital; i subratlla, finalment, entre molts altres aspectes, la importància de la funció social de la propietat. 
Parlar de la crisi ambiental és parlar, com ho fa l'encíclica, de crisi d'un sistema engendrat per la Modernitat, fonamentat en dos grans idees, la confiança absoluta en la capacitat de conèixer el funcionament del planeta com si fos una màquina $i$, a partir d'aquí, la capacitat de dominar-lo a través de la tècnica, així com, en segon lloc, la convicció sobre el caràcter il-limitat dels recursos disponibles. Aquest paradigma tecnocràtic ha estat la base de la idea d'un creixement indefinit o il·limitat, dominant en el context de la globalització sota l'expressió amable del desenvolupament sostenible. En aquest context, la crisi ambiental té una sortida purament tècnica, a través d'una millora en l'eficiència humana en l'ús dels recursos, sense prendre en consideració els considerables desequilibris en l'assignació dels recursos i el progressiu deteriorament del planeta a conseqüència de l'explotació massiva i de les tecnologies en ús, que acaben tenir efectes no previstos i, sovint, devastadors.

En aquest context, el Papa conclou que "[n]o hi ha dues crisis separades, una ambiental i una altra social, sinó una sola i complexa crisi socioambiental. Les línies per a la solució requereixen una aproximació integral per combatre la pobresa, per tornar la dignitat als exclosos i simultàniament per tenir cura de la natura" (139). Aquesta diagnosi ve acompanyada per un marc analític basat en una sèrie de conceptes desplegats en el camp de les concepcions alternatives de la crisi ambiental, des dels moviments socials fins a sectors acadèmics contrahegemònics, particularment en el camp de la sociologia, l'economia, l'antropologia i, darrerament, també del dret. Així, l'encíclica es refereix a idees com les de justícia ambiental, deute ecològic o decreixement, i defensa principis jurídics amenaçats com el de precaució i el de responsabilitats comunes però diferenciades. Tot plegat proporciona una visió alternativa a la dinàmica de creixement permanent $\mathrm{i}$ irresponsable que el sistema polític i econòmic global propugnen, atrapant en la inacció als responsables polítics internacionals, impotents més enllà dels documents de bones intencions que, de tant en tant, són capaços de subscriure.

Des del punt de vista jurídic, cal subratllar aquí que hi ha dos principis en el dret internacional del medi ambient, formulats en la Declaració de Rio de Janeiro de 1992, que són objecte d'atacs directes per part dels estats del Nord i de les grans empreses transnacionals, els ja esmentats de responsabilitats comunes però diferenciades i de precaució. L'encíclica els defensa tots dos, d'acord amb una idea de no regressió dels llindars de protecció que ha estat impugnada en el context de les mesures adreçades a 
estimular l'activitat econòmica en el context de crisi financera que s'ha consolidat des de 2008. Aquesta idea de no cedir davant de la pressió dels poders dominants en els sistemes de presa de decisions de la governança econòmica mundial ve acompanyada del suggeriment de la necessitat d'una revolució cultural que ens acosti, com a societat global, a un compromís amb la cura del planeta i amb la justícia social. En aquest sentit, l'encíclica s'aparta d'una simple aproximació gerencial a la qüestió ambiental per demanar un canvi cultural profund.

D'aquesta manera, l'encíclica promou una ecologia integral ambiental, econòmica i social, però també cultural, tant en el sentit de tenir cura de les riqueses culturals de la humanitat, com en el sentit d'incorporar la perspectiva dels drets dels pobles i les cultures, amb una reivindicació explícita a l'aportació històrica i actual de les comunitats indígenes en la cura dels seus territoris, així com la defensa dels seus drets sobre els mateixos, greument amenaçats per una gran quantitat de projectes extractius, agrícoles o ramaders o, fins i tot, turístics que ni necessiten ni han demanat ni consentit. També hi apareix una ecologia de la vida quotidiana, en les ciutats, basada en la participació i en la inclusió social, amb especial referència al dret a l'habitatge o a la dignificació del transport públic. En aquest context, el document apel·la tant a la solidaritat intergeneracional com la solidaritat intrageneracional.

En el camp de la política, l'encíclica critica la debilitat de la resposta internacional a la crisi ambiental, així com la supeditació de la política a l'economia. En aquest context, com a contrapunt a les decepcions derivades de les darreres cimeres ambientals, expressa la necessitat d'arribar a acords en relació amb la programació d'una agricultura sostenible i diversificada, el desenvolupament d'energies netes i renovables, el foment d'una major eficiència energètica, la promoció d'una gestió més adequada dels recursos forestals i marins, la governança dels oceans o la garantia per a tothom de l'accés a l'aigua potable. El Papa posa un èmfasi especial en el tema del canvi climàtic i critica, per exemple, el mercat d'emissions, que pot donar lloc a noves formes d'especulació i ser poc útil pel que fa a la reducció d'emissions.

D'altra banda, es fa una crida directa a reformular la governança mundial, que limiti els poders econòmics i financers. Així, el document fa referència a la necessitat de diàleg $\mathrm{i}$ transparència en els processos de presa de decisions, tot subratllant la importància de la participació dels afectats, la qual cosa requereix una informació adequada dels diferents aspectes de les opcions presents i dels diferents riscos i possibilitats, i no s'ha de reduir 
a la decisió inicial sobre un projecte, sinó que implica també accions de seguiment i control constant. Tot plegat conclou en un canvi de model global pel que fa a la governança del metabolisme social, de profundes implicacions socials, econòmiques, polítiques i culturals.

En resum, es tracta d'un text políticament molt important, valent i radical, l'impacte real del qual caldrà apreciar en els pròxims anys. Cal recuperar, per concloure, que Laudato $S i$ ' significa una presa de posició alineada amb les posicions contrahegemòniques en relació amb la resposta social necessària davant de la crisi ambiental, que és una crisi sistèmica, de model. Que un actor internacional de la importància del cap de l'Església catòlica adopti aquest punt de vista $\mathrm{i}$ faci una crítica tan profunda i comprensiva de la realitat política i econòmica global és un esdeveniment que convida a la reflexió dels governants, però també dels actors socials i econòmics, així com dels acadèmics. 


\section{EDITORIAL}

\section{Laudato Si'}

En el contexto post Rio+20, con una crisis económica persistente que, paradójicamente, parece reforzar las dinámicas extractivistas y desarrollistas del metabolismo social global, las posiciones políticas claras y determinadas en relación con las necesidades de cambios profundos en la relación entre los seres humanos y la naturaleza, y en la distribución de los recursos no han sido abundantes en la arena internacional. Por esta razón, la carta encíclica Laudato Si' del Papa Francisco es un documento de primera importancia, que puede tener una proyección muy relevante en los debates ambientales futuros, ya que, justamente, recapitulando una doctrina precedente que se ha ido generando en el marco de las iglesias cristianas y, particularmente, la católica, en relación con la crisis ambiental, propone un enfoque radical sobre esta cuestión, con referencias significativas a conceptos e ideas que forman parte de las posiciones alternativas en el debate, como deuda ecológica o decrecimiento.

El Papa Francisco encabeza la Iglesia Católica, lo que le concede un liderazgo moral que va más allá de la comunidad católica estricta. Además, no debe olvidarse su condición de jefe de estado, a pesar de que se trate de un estado minúsculo, de menos de medio quilómetro cuadrado y menos de mil habitantes, la Ciudad del Vaticano. No es banal que un jefe de estado, por pequeño que sea éste, emita un documento oficial en el que expresa su opinión sobre la crisis ambiental de una manera tan radical. Aún lo es menos que ese jefe de estado encabece una de las confesiones religiosas más extendidas y de una tradición más densa y consolidad. Por este motivo, no puede sorprender el impacto que tiene y ha de tener la encíclica Laudato $\mathrm{Si}^{\prime}$, saludada por muchos ambientalistas como una aportación significativa y valiente al debate internacional sobre la manera de afrontar la crisis ambiental.

La encíclica hace un diagnóstico completo del estado del medio ambiente y apunta las causas principales de la crisis ambiental - concepto que también aparece literalmente en el texto-, así como sus efectos, y marca una serie de líneas políticas, a partir de unos cuantos conceptos clave en los grandes debates del momento. Es cierto que la encíclica reposa sobre una amplia serie de antecedentes, que van desde encíclicas de papas anteriores, hasta documentos episcopales de todo el mundo, considerando las 
aportaciones más allá de la misa Iglesia Católica, como las del Patriarca Ecuménico Bartolomé. Aun así, el carácter comprehensivo y la profundidad de Laudato Si', así como su estructurada radicalidad, convierten a este documento en una novedad de impacto difícilmente negligible en el ámbito del Derecho ambiental, más cuando éste está sometido a presiones regresivas en el contexto de las medidas de estímulo poco imaginativas que se toman para afrontar la crisis económica. Se trata de un documento valiente y radical; valiente porque adopta una posición bien diferenciada de lo que es la corriente dominante en los discursos de los estados, y radical porque pone el acento en la raíz del problema, esto es, el mismo funcionamiento del metabolismo social en el contexto del sistema-mundo capitalista.

La encíclica repasa los distintos problemas que afectan al medio ambiente mundial: desde la contaminación del aire y el agua a los residuos, desde la deforestación a la pesca insostenible o los riesgos de la sustitución de los bosques y zonas húmedas por monocultivos; pone el acento, por su extrema gravedad, en el cambio climático y la pérdida de la diversidad. Sin embargo, subraya que las cuestiones ambientales no pueden afrontarse aisladamente. El estado del medio ambiente es la otra cara del modelo de reproducción social, de la manera cómo la organización social aprovecha los recursos naturales, como interactúa con ellos para generar los productos que requiere para satisfacer sus necesidades, cómo genera y utiliza la energía que necesita para esta trasformación, y cómo gestiona los residuos que se derivan de este proceso.

Por este motivo, coincidiendo con el enfoque de la problemática ambiental que se propone desde las diferentes perspectivas basadas en la justicia ambiental, la encíclica subraya el aspecto social de la cuestión. Así, se refiere a los desplazados forzosos a consecuencia del cambio climático; critica la privatización del agua y definede el acceso al agua potable como derecho humano básico, apunta a que el control del agua por parte de grandes empresas se convertirá en una de las principales fuentes de conflictos en este siglo; denuncia el deterioro de la calidad de la vida humana y la degradación social, especialmente en las megaciudades, así como la falta de equidad en la disponibilidad y el consumo de energía y otros servicios; señala los impactos sociales derivados de las dinámicas del mundo digital; y subraya, finalmente, entre muchos otros aspectos, la importancia de la función social de la propiedad.

Hablar de crisis ambiental es hablar, como lo hace la encíclica, de crisis de un sistema engendrado por la Modernidad, fundado en dos grandes ideas, la confianza absoluta en 
la capacidad de conocer el funcionamiento del planeta como si fuera una máquina y, a partir de aquí, la capacidad de dominarlo a través de la técnica; así como, en segundo lugar, la convicción sobre el carácter ilimitado de los recursos disponibles. Este paradigma tecnocrático ha sido la base de la idea de un crecimiento indefinido o ilimitado, dominante en el contexto de la globalización bajo la expresión amable del desarrollo sostenible. En este contexto, la crisis ambiental tiene una salida puramente técnica, a través de la mejora en la eficiencia humana en el uso de los recursos, sin tomar en consideración los considerables desequilibrios en la asignación de los recursos y el progresivo deterioro del planeta a consecuencia de la explotación masiva y de las tecnologías en uso, que acaban teniendo efectos no previstos y, a menudo, devastadores. En este contexto, el Papa concluye que "[n]o hay dos crisis separadas, una ambiental y la otra social, sino una sola y compleja crisis socioambiental. Las líneas para la solución requieren una aproximación integral para combatir la pobreza, para devolver la dignidad a los excluidos y simultáneamente tener cuidado de la naturaleza" (139). Este diagnóstico viene acompañado por un marco analítico basado en una serie de conceptos desplegados en el campo de las concepciones alternativas de la crisis ambiental, dede los movimientos sociales hasta sectores académicos contrahegemónicos, particularmente en el campo de la sociología, la economía, la antropología y, últimamente, también del Derecho. Así, la encíclica se refiere a ideas como las de justicia ambiental, deuda ecológica o decrecimiento, y defiende principios jurídicos amenazados como el de precaución o el de responsabilidades comunes pero diferenciadas. Todo ello proporciona una visión alternativa a la dinámica de crecimiento permanente e irresponsable que el sistema político y económico global propugnan, atrapando en la inacción a los responsables políticos internacionales, impotentes más allá de los documentos de buenas intenciones que, de tanto en cuando, son capaces de suscribir.

Desde el punto de vista jurídico, debe subrayarse aquí que hay dos principios en el Derecho internacional del medio ambiente, formulados en la Declaración de Rio de Janeiro de 1992, que son objeto de ataques directos por parte de los estados del Norte y de las grandes empresas transnacionales, los ya mencionados de responsabilidades comunes pero diferenciadas, y de precaución. La encíclica defiende ambos, de acuerdo con una idea de no regresión de los umbrales de protección que ha sido impugnado en el contexto de las medidas encaminadas a estimular la actividad económica en el contexto 
de la crisis financiera que se ha consolidado desde 2008. Esta idea de no ceder a la presión de los poderes dominantes en los sistemas de toma de decisiones de la gobernanza económica mundial viene acompañada de la sugerencia de la necesidad de una revolución cultural que nos acerque, como sociedad global, a un compromiso con el cuidado del planeta y con la justicia social. En este sentido, la encíclica se aparta de una simple aproximación gerencial a la cuestión ambiental para pedir un cambio cultural profundo.

De este modo, la encíclica promueve una ecología integral ambiental, económica y social, pero también cultural, tanto en el sentido de tener cuidado de las riquezas culturales de la humanidad, como en el sentido de incorporar la perspectiva de los derechos de los pueblos y las culturas, en una reivindicación explícita de la aportación histórica y actual de las comunidades indígenas en el cuidado de sus territorios, así como la defensa de sus derechos sobre los mismos, gravemente amenazados por una gran cantidad de proyectos extractivos, agrícolas y ganaderos, o, incluso, turísticos, que no necesitan ni han pedido ni consentido. También aparece una ecología de la vida cotidiana, en las ciudades, basada en la participación y en la inclusión social, con especial referencia al derecho a la vivienda o a la dignificación del transporte público. En este contexto, el documento apela tanto a la solidaridad intergeneracional, como a la solidaridad intrageneracional.

En el campo de la política, la encíclica critica la debilidad de la respuesta internacional a la crisis ambiental, así como la supeditación de la política a la economía. En este contexto, como contrapunto a las decepciones derivadas de las últimas cumbres ambientales, expresa la necesidad de llegar a acuerdos en relación con la programación de una agricultura sostenible y diversificada, el desarrollo de energías limpias y renovables, el fomento de una mayor eficiencia energética, la promoción de una gestión más adecuada de los recursos forestales y marinos, la gobernanza de los océanos o la garantía para todos del acceso al agua potable. El Papa pone especial énfasis en el tema del cambio climático y critica, por ejemplo, el mercado de emisiones, que puede dar lugar a nuevas formas de especulación y ser poco útil en relación con la reducción de las emisiones.

Por otra parte, se apela a una reformulación de la gobernanza mundial, que limite a los poderes económicos y financieros. Así, el documento se refiere a la necesidad de diálogo y de transparencia en los procesos de toma de decisiones, subrayando la 
importancia de la participación de los afectados, lo que requiere una información adecuada de los diferentes aspectos de las opciones presentes y de los riesgos y posibilidades, y no debe reducirse a la decisión inicial sobre el proyecto, sino que implica también acciones de seguimiento y control constante. Todo ello concluye en un cambio de modelo global en relación con la gobernanza del metabolismo social, de profundas implicaciones sociales, económicas, políticas y culturales.

En resumen, se trata de un texto políticamente muy importante, valiente y radical, cuyo impacto real será apreciado en los próximos años. Debe recuperarse aquí, para concluir, que Laudato $\mathrm{Si}^{\prime}$ significa una toma de posición alineada con las posiciones contrahegemónicas en relación con la respuesta social necesaria ante la crisis ambiental, que es una crisis sistémica, de modelo. Que un actor internacional de la importancia del Papa adopte este punto de vista y haga una crítica tan profunda y comprehensiva de la realidad política y económica global es un acontecimiento que invita a la reflexión de los gobernantes, pero también de los actores sociales y económicos, así como de los académicos. 